\title{
Tetramer guided, cell sorter assisted production of clinical grade autologous NY-ESO-1 specific $\mathrm{CD} 8^{+} \mathrm{T}$ cells
}

Seth M Pollack ${ }^{1,2^{*}}$, Robin L Jones ${ }^{1,2}$, Erik A Farrar ${ }^{1}$, Ivy P Lai ${ }^{1,8}$, Sylvia M Lee ${ }^{1,2}$, Jianhong Cao ${ }^{1}$, Venu G Pillarisetty ${ }^{1,3}$, Benjamin L Hoch ${ }^{4}$, Ashley Gullett ${ }^{4}$, Marie Bleakley ${ }^{1,5}$, Ernest U Conrad III', Janet F Eary ${ }^{7}$, Kendall C Shibuya ${ }^{1}$, Edus H Warren ${ }^{1,2}$, Jason N Carstens ${ }^{1}$, Shelly Heimfeld ${ }^{1}$, Stanley R Riddell ${ }^{1,2,8}$ and Cassian Yee Y $^{1,2,9^{*}}$

\begin{abstract}
Background: Adoptive T cell therapy represents an attractive modality for the treatment of patients with cancer. Peripheral blood mononuclear cells have been used as a source of antigen specific $T$ cells but the very low frequency of T cells recognizing commonly expressed antigens such as NY-ESO-1 limit the applicability of this approach to other solid tumors. To overcome this, we tested a strategy combining IL-21 modulation during in vitro stimulation with first-in-class use of tetramer-guided cell sorting to generate NY-ESO-1 specific cytotoxic T lymphocytes (CTL).
\end{abstract}

Methods: CTL generation was evaluated in 6 patients with NY-ESO-1 positive sarcomas, under clinical manufacturing conditions and characterized for phenotypic and functional properties.

Results: Following in vitro stimulation, T cells stained with NY-ESO-1 tetramer were enriched from frequencies as low as $0.4 \%$ to $>90 \%$ after single pass through a clinical grade sorter. NY-ESO-1 specific T cells were generated from all 6 patients. The final products expanded on average 1200-fold to a total of 36 billion cells, were oligoclonal and contained $67-97 \% \mathrm{CD}^{+}$, tetramer ${ }^{+} \mathrm{T}$ cells with a memory phenotype that recognized endogenous NY-ESO-1.

Conclusion: This study represents the first series using tetramer-guided cell sorting to generate T cells for adoptive therapy. This approach, when used to target more broadly expressed tumor antigens such as WT-1 and additional Cancer-Testis antigens will enhance the scope and feasibility of adoptive T cell therapy.

Keywords: Adoptive T cell therapy, NY-ESO-1, Synovial sarcoma, Myxoid, Liposarcoma, Immunotherapy, Antigen specific T cells, Tetramer, Influx cell sorting

\section{Background}

The use of antigen-specific T cells for adoptive immunotherapy of patients with advanced cancers is emerging as a promising treatment modality [1-3]. Recent trials using genetic modification of $\mathrm{T}$ cells to introduce chimeric antigen receptors (CAR's) or T cell receptors (TCR's) and redirect their target specificity to tumor cells can be remarkably effective in reducing tumor burden and providing durable remissions in $\mathrm{B}$ cell malignancies and

\footnotetext{
* Correspondence: spollack@fhcrc.org; cyee@mdanderson.org

${ }^{1}$ Clinical Research Division, D3-100 Fred Hutchinson Cancer Research Center, 1100 Fairview Ave, Seattle, WA 98109, USA

${ }^{2}$ Department of Medicine, University of Washington, Seattle, WA, USA

Full list of author information is available at the end of the article
}

some solid tumors [4-10]. However, the regulatory and logistical hurdles of gene transfer can be prohibitive and issues such as receptor mispairing (for TCRs), target antigen affinity, and serious, occasionally life-threatening, even lethal on-target toxicities remain to be fully addressed [11,12]. Although once fully characterized, these genetically modified approaches may be quite expedient, they first require a priori possession of the relevant receptor sequence from the cognate antibody for a CAR or a $\mathrm{T}$ cell clone for a TCR as well as rigorous validation, all of which limit the flexibility of this approach and incur significant obstacles to bringing a cell product to the clinic.

An alternative approach, involves the isolation of circulating endogenous antigen-specific $\mathrm{T}$ cells from the 
peripheral blood (Endogenous T Cell Therapy or ETC) and ex vivo expansion for adoptive transfer. Although these tumor-reactive $\mathrm{T}$ cells can be present at very low frequency, the feasibility of isolating and expanding endogenous antigen-specific CTL from the peripheral blood of patients for adoptive therapy has been demonstrated in trials targeting melanocyte antigens such as gp100 and MART-1 in melanoma, with intriguing evidence of clinical efficacy $[2,13]$. The endogenous frequency of CTL targeting melanocyte antigens such as MART-1 is particularly high (up to 1\%) enabling facile generation of MART-1specific $\mathrm{T}$ cells using conventional approaches $[2,13,14]$. However, for more commonly expressed tumor antigens such as WT-1, MAGE family antigens and NY-ESO-1, the generation of antigen-specific cytotoxic $\mathrm{T}$ lymphocytes (CTL) has been labor and resource-intensive and largely unsuccessful on a routine basis due to their relatively rare endogenous precursor frequencies $(<1: 10,000)$.

With the exception of MART-1 and some tumorassociated viral antigens, generation of antigen-specific $\mathrm{T}$ cells using a conventional approach involving repeated cycles of autologous PBMC stimulation using peptidepulsed dendritic cells (DC's) often fails to enrich low frequency tumor-reactive CTL to numbers sufficient for expansion and adoptive transfer.

To address this issue, we previously discovered that the addition of IL-21 during the initial priming period could increase the total number of antigen-specific CD8 $\mathrm{T}$ cells by $>20$-fold and, at the clonal level, enrich for a population of high-affinity CD8 $\mathrm{T}$ cells with sustained elevation of CD28 levels and a helper-independent phenotype. This enrichment can be further enhanced by depletion of CD25+ Treg cells from the responder PBMC prior to in vitro stimulation [15-17], leading to a synergistic increase in the yield of antigen-specific CTL to 2-300 fold greater than those cultures that were CD25 replete and not exposed to IL-21 $[18,19]$.

Therefore, to broaden the scope of patients eligible for adoptive therapy and the tumors that can be treated, we chose to target a prototypic cancer-testis antigen, NYESO-1, expressed by several solid tumor malignancies, including breast cancer, lung cancer, melanoma, sarcoma and ovarian cancer. We developed a strategy where NYESO-1 specific T cells were first enriched through in vitro stimulation of CD25 depleted PBMC [17] with peptide pulsed dendritic cells in the presence of IL-21, followed by tetramer guided cell sorting to isolate and expand autologous NY-ESO-1-specific CTL from the peripheral blood of patients with sarcoma under clinically compliant manufacturing conditions.

To determine whether highly avid, oligoclonal NY-ESO-1 specific $\mathrm{CD}^{+}$T cells recognizing NY-ESO-1 positive tumor cell lines could be consistently isolated from patients who might benefit from NY-ESO-1 targeted therapy, we focused on patients with synovial sarcoma (SS) and myxoid/round cell liposarcoma (MRCL) because these tumors homogenously express NY-ESO-1, often with high intensity [20,21]. We successfully isolated NY-ESO-1 specific T cells from 6 of 6 , NY-ESO-1 expressing sarcoma patients using a clinical grade INFLUX cell sorter (Becton Dickson) and propagated these highly enriched populations to sufficient numbers for adoptive immunotherapy.

\section{Results}

\section{Patient characteristics and leukapheresis yield}

Isolation and expansion of NY-ESO-1 specific $\mathrm{T}$ cells from leukapheresis products was attempted in six patients with SS $(n=5)$ and MRCL $(n=1)$ that expressed NY-ESO-1 in their diagnostic tumor biopsies (Table 1). The median age of these patients was 44 (26-48), which is older than the reported median age for SS patients [22]. Prior to leukapheresis, two of the six patients had received chemotherapy including doxorubicin and ifosfamide (A/I). The remaining four patients underwent leukapheresis before receiving chemotherapy. A range of $5 \times 10^{9}-13.6 \times 10^{9}$ mononuclear cells was obtained by leukapheresis from each of the six patients. The yield did not correlate with prior chemotherapy, suggesting that prior chemotherapy was not a significant barrier to obtaining an adequate leukapheresis collection (Table 1). We depleted CD25 $5^{+}$cells from an aliquot of $2 \times 10^{9}$ cells to remove regulatory $\mathrm{T}$ cells prior to establishing $\mathrm{T}$ cell cultures resulting in a $1-2 \log$ reduction in $\mathrm{CD} 25^{+}$cells (data not shown). The average yield after CD25 depletion was $1.34 \times 10^{9}$ cells (range 0.99 to $1.56 \times 10^{9}$ ).

\section{Production of clinical grade NY-ESO-1 specific T cells by cell sorting}

The strategy to isolate NY-ESO-1 specific T cells from PBMC is illustrated in Figure 1 . For patient \#1, three 48 well plates were plated with $\mathrm{T}$ cells and peptide pulsed DC's. After two stimulations, each individual well was stained with the NY-ESO-1 tetramer and analyzed by flow cytometry. NY-ESO-1 tetramer positive $\mathrm{CD}^{+} \mathrm{T}$ cells were not observed in the starting leukapheresis product (detection threshhold $<0.01 \%$, Figure $1 \mathrm{~A}$ ), however 3 of the 144 stimulated wells contained NY-ESO-1 tetramer positive $\mathrm{T}$ cells at a frequency of $>0.5 \%$ (Figure $1 \mathrm{~B}$ ). These three wells were pooled and the tetramer binding $\mathrm{T}$ cells were sorted, expanded initially in a T25 flask and subsequently in Lifecell Bags in the CPF. The final product was $>94 \% \mathrm{CD}^{+}$ and NY-ESO-1 tetramer positive and specifically lysed T2 cells pulsed with NY-ESO-1 157-165 peptide and the NY-ESO-1 expressing melanoma cell line, MelA375 (see Figure $1 \mathrm{C}$ and $\mathrm{D}$ ).

Similar to patient \#1, none of the remaining 5 patients had detectable NY-ESO-1 specific $\mathrm{T}$ cells by tetramer staining of starting PBMC (data not shown). One or two 
Table 1 Leukapheresis yield in advanced sarcoma patients

\begin{tabular}{lllllll}
\hline & $\begin{array}{l}\text { Sarcoma } \\
\text { subtype }\end{array}$ & Age & $\begin{array}{l}\text { Chemotherapy prior } \\
\text { to leukapharesis }\end{array}$ & Sites of disease & $\begin{array}{l}\text { Leukapharesis } \\
\text { yield }(\times \mathbf{1 0} \mathbf{9})\end{array}$ & $\begin{array}{l}\text { Yield of CD25 } \\
\text { depletion }(\times \mathbf{1 0} \mathbf{9})\end{array}$ \\
\hline Patient 1 & SS & 47 & None & Soft tissue, lung, brain & 7.11 & 0.99 \\
Patient 2 & MRCL & 35 & Rtx & Bone, soft tissue, lung & 6.9 & 1.44 \\
Patient 3 & SS & 48 & A/l, HD Ifos, Rtx & Brain, lung & 5.14 & 1.2 \\
Patient 4 & SS & 46 & A/INincristine, Rtx/Ifos & Lung & 14 & 1.365 \\
Patient 5 & SS & 26 & None & Lung, kidney, soft tissue & 11.2 & 1.56 \\
Patient 6 & SS & 42 & None & Recurrent, locally advanced axillary disease & 13.76 & 1.46 \\
\hline
\end{tabular}

Rtx - Radiation therapy; A/I - Adriamycin and Ifosfamide; Gem/tax - gemcitabine and docetaxel; Doxil - liposomal doxorubicin; A/I/DTIC - Adriamycin, Ifosfamide and Decarbazine.

48-well plates were seeded with $\mathrm{T}$ cells and stimulated with NY-ESO-1 $157-165$ peptide pulsed DC's. After two stimulation cycles, at least three wells (range 3 to 7 ) from each patient contained NY-ESO-1 tetramer positive cells at a frequency of $0.01-8.05 \%$ (Table 2). Overall, the average number of wells per patient that contained NY-ESO-1 tetramer positive cells was 3.8 (out of total of 48-144 wells) and the mean frequency of NY-ESO-1 tetramer positive cells in these wells was $1.67 \%$. This contrasts with the robust response seen with MART-1 where under similar culture conditions typically every well will have $>1 \%$ tetramer positive cells, and occasional wells will exhibit a robust MART-1-specific response with $>20 \%$ tetramer positive cells (Additional file 1: Figure S1).
The flow sorted NY-ESO-1-specific $\mathrm{T}$ cells were then stimulated with anti CD3 mAb in T25 flasks, which yielded an average of $197 \times 10^{6}$ (range 73 to $331 \times 10^{6}$ ) $\mathrm{T}$ cells after 14 days. Larger volume expansions were then performed in either GREX containers or cell culture bags in the CPF. For two of the patients (\#4 and \#6), we performed the large volume expansion on T cells sorted from only a fraction of the positive wells. The average bag or GREX REP produced a 1204-fold expansion (range 6501754 fold). All cell products were expanded to over $2 \times$ $10^{10}$ cells, and except for patient \#5, the final cell product was $>85 \% \mathrm{CD}^{+}$and NY-ESO-1 tet $^{+}$(range 67.2-97.1\%) (Table 2 and Additional file 1: Figure S2). Based on these percentages, the absolute number of antigen specific
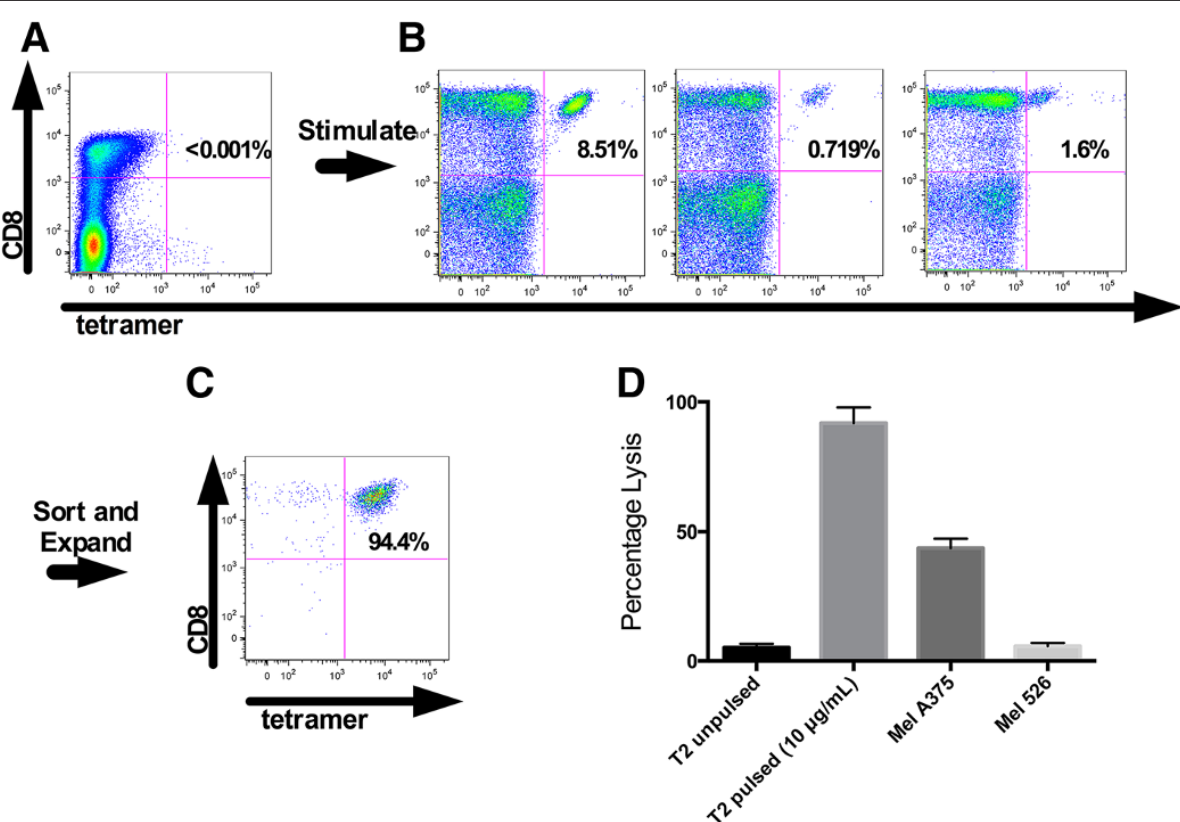

Figure 1 Representative production of clinical grade NY-ESO-1 specific T cell products from patient 1. A. No detectable cells are observed with CD8 and Tetramer staining of untreated PBMC from patient 1. B. Small CD8 ${ }^{+}$and Tetramer ${ }^{+}$were observed in 3 wells of three 48 well plates after 2 stimulations using peptide pulsed dendritic cells. C. The 3 positive wells were sorted using the clinical grade cell sorted and underwent 2 expansions. CD8 and tetramer staining of the final product is shown. D. The final product was able to lyse peptide pulsed targets as well as an endogenously NY-ESO-1 expressing tumor line (NY-ESO-1). Mel 526 is an HLA-A2 ${ }^{+}$, NY-ESO-1 ${ }^{-}$tumor line used as a control. 
Table 2 Generation of clinical grade products

\begin{tabular}{|c|c|c|c|c|c|c|c|c|c|c|}
\hline & $\begin{array}{l}\text { Number } \\
\text { of plates }\end{array}$ & $\begin{array}{l}\text { Number } \\
\text { positive } \\
\text { wells }\end{array}$ & $\begin{array}{l}\text { Least \% } \\
\text { positive } \\
\text { sorted }\end{array}$ & $\begin{array}{l}\text { Largest \% } \\
\text { positive } \\
\text { (all sorted) } \\
\end{array}$ & $\begin{array}{l}\text { Mean } \% \\
\text { positive }\end{array}$ & $\begin{array}{l}\text { Number of wells } \\
\text { used for expansion } \\
\text { to final product }\end{array}$ & $\begin{array}{l}\text { Total cells } \\
\text { after mini-REP } \\
(\times 10 \wedge 6)\end{array}$ & $\begin{array}{l}\text { Bag REP vs. } \\
\text { GREX REP }\end{array}$ & $\begin{array}{l}\text { Cells started for } \\
\text { large volume } \\
\text { expansion }\left(\times 10^{\wedge} 6\right)\end{array}$ & $\begin{array}{l}\text { Final cell } \\
\text { number } \\
\left(\times 10^{\wedge} 9\right)\end{array}$ \\
\hline Patient 1 & 3 & 3 & $0.62 \%$ & $8.05 \%$ & $3.39 \%$ & 3 & 230 & Bag & 33 & 57.9 \\
\hline Patient 2 & 1 & 5 & $0.57 \%$ & $1.90 \%$ & $1.00 \%$ & 5 & 73 & GREX & 68 & 44.2 \\
\hline Patient 3 & 1 & 7 & $0.01 \%$ & $5.23 \%$ & $1.23 \%$ & 7 & 224 & GREX & 25 & 26.4 \\
\hline Patient 4 & 2 & 6 & $0.11 \%$ & $3.68 \%$ & $1.03 \%$ & 4 & 157 & GREX & 19 & 20.7 \\
\hline Patient 5 & 2 & 3 & $0.07 \%$ & $1.55 \%$ & $0.57 \%$ & 3 & 331 & GREX & 32 & \\
\hline Patient 6 & 2 & 5 & $0.11 \%$ & $7.24 \%$ & $2.80 \%$ & 1 & 169 & Bag & 18 & 24.6 \\
\hline Mean & 1.8 & 4.8 & $0.2 \%$ & $4.6 \%$ & $1.7 \%$ & 3.8 & 197.3 & & 32.4 & 34.8 \\
\hline
\end{tabular}

$\mathrm{CD}^{+}$, tet $^{+}$cells in each product ranged from $16.7 \times 10^{9}$ to $54.7 \times 10^{9}$. Cell doses in prior studies performed by our program that have led to clinical responses used $10^{10}$ cells $/ \mathrm{m}^{2}$, suggesting this strategy for isolating and expanding NY-ESO-1 specific $\mathrm{T}$ cells can yield therapeutically relevant cell doses.

Phenotype and function of NY-ESO-1-specific CD8 ${ }^{+}$T cells Exposure to IL-21 during in vitro priming has previously been shown to enrich for a population of $\mathrm{CD}^{+} \mathrm{T}$ cells with high affinity recognition of tumor antigen, effector function, and expression of co-stimulatory molecules such as CD28 $[18,19]$. Phenotype analysis of the final expanded NY-ESO-1 specific T cell products demonstrated expression of CD45RO, CD27 and CD28 on the majority of $\mathrm{CD}^{+} \mathrm{T}$ cells, and the absence of CCR7 or CD62L, consistent with an effector memory like phenotype. In almost all cases, a subpopulation of CD127 ${ }^{\text {hi }}$ also appears in the final $\mathrm{T}$ cell product also suggesting a memory-like phenotype (see Additional file 1: Figure S3).

We evaluated the function of the NY-ESO-1-specific T cell products by assaying specific lysis of T2 (HLA-A $2^{+}$) targets pulsed with titrated concentrations of NY-ESO-1 peptide as well as the NY-ESO- $1^{+}$tumor cell line Mel A375. All cell products exhibited specific lysis of T2 cells pulsed with $<0.01 \mu \mathrm{g} / \mathrm{ml}$ of NY-ESO-1 peptide and of the Mel A375 tumor cells that endogenously expressed NY-ESO-1 (Figure 2A). The lytic ability of NY-ESO-1 specific CTL generated from the sarcoma patients in this study was comparable to a high affinity NY-ESO-1-specific $\mathrm{T}$ cell clones that we previously isolated [23], and to $\mathrm{T}$ cells transduced with the high affinity mutant $\alpha \mathrm{LY}$ NYESO-1 specific TCR and sorted to $>80 \%$ purity (Figure $2 \mathrm{~A}$ and $\mathrm{B})$. In response to T2 cells pulsed with NY-ESO-1 peptide, the $\mathrm{T}$ cell products from all patients secreted IFN- $\gamma$ (mean $305 \mathrm{pg} / \mathrm{mL}$, range 143 to $425 \mathrm{pg} / \mathrm{mL}$ ) and TNF alpha (mean $674.9 \mathrm{pg} / \mathrm{mL}$, range 313.4 to $1113.9 \mathrm{pg} /$ $\mathrm{mL}$ ) (Additional file 1: Figure S4). In each case, the NYESO-1 specific CTL lines were also confirmed to lyse a SS tumor line (SYO-1) and a MRCL tumor line (402) which had been transfected with the gene for $\mathrm{A}^{*} 0201$ (Additional file 1: Figure S5).

Thus, the avidity and effector function of antigenspecific CTL derived from the peripheral blood is sufficient to recognize endogenous tumor associated antigens and compares favorably to a clinically relevant high affinity mutant TCR. In order to confirm that NY-ESO-1 specific cells could be generated in patients without NY-ESO-1 expressing tumors, we also made cells through this process in two healthy donors which were also able to recognize peptide pulsed T2's and endogenously expressed peptide.

\section{Clonality of products}

We next assessed the clonality of the T cell products using TCR V $\beta$ spectratyping. All products were oligoclonal with a range of high intensity peaks from 2 (patient \#2) to 15 (patient \#4) (Additional file 1: Figure S6). In order to better quantify the TCR composition of these products, deep sequencing of the TCR was performed on patient \#1 and patient \#4 (Adaptive Biotechnologies). Despite the fact that the cell product from patient \#1 was comprised of tetramer positive $\mathrm{T}$ cells sorted and expanded from 3 individual 48 wells, the final cell product was almost entirely comprised of a single dominant clone constituting $86.3 \%$ of the TCR sequence reads. The next 5 most common sequences comprised $7.3 \%$ of the total sequences observed. A total of 235 were observed in the infusion product (Additional file 1: Figure S7). The product from patient \#4 combined 4 wells and also contained a dominant clone ( $85.4 \%$ of the sequences). The next most common 6 clones comprised $9.05 \%$ of the product and a total of 435 sequences were observed. In composite, our data demonstrates the feasibility and reproducibility of generating a single clone dominant but still oligoclonal, tumor-reactive, NY-ESO-1 specific CD8 ${ }^{+}{ }^{-} \mathrm{T}$ cells from sarcoma patients using clinical cell sorting technology.

\section{Discussion}

In light of the significant clinical responses observed among patients receiving antigen-specific T cells recognizing 


\section{A Patient 1}

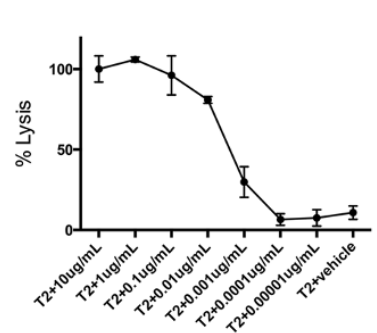

Patient 2

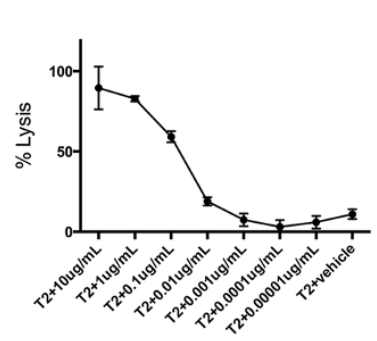

Patient 3
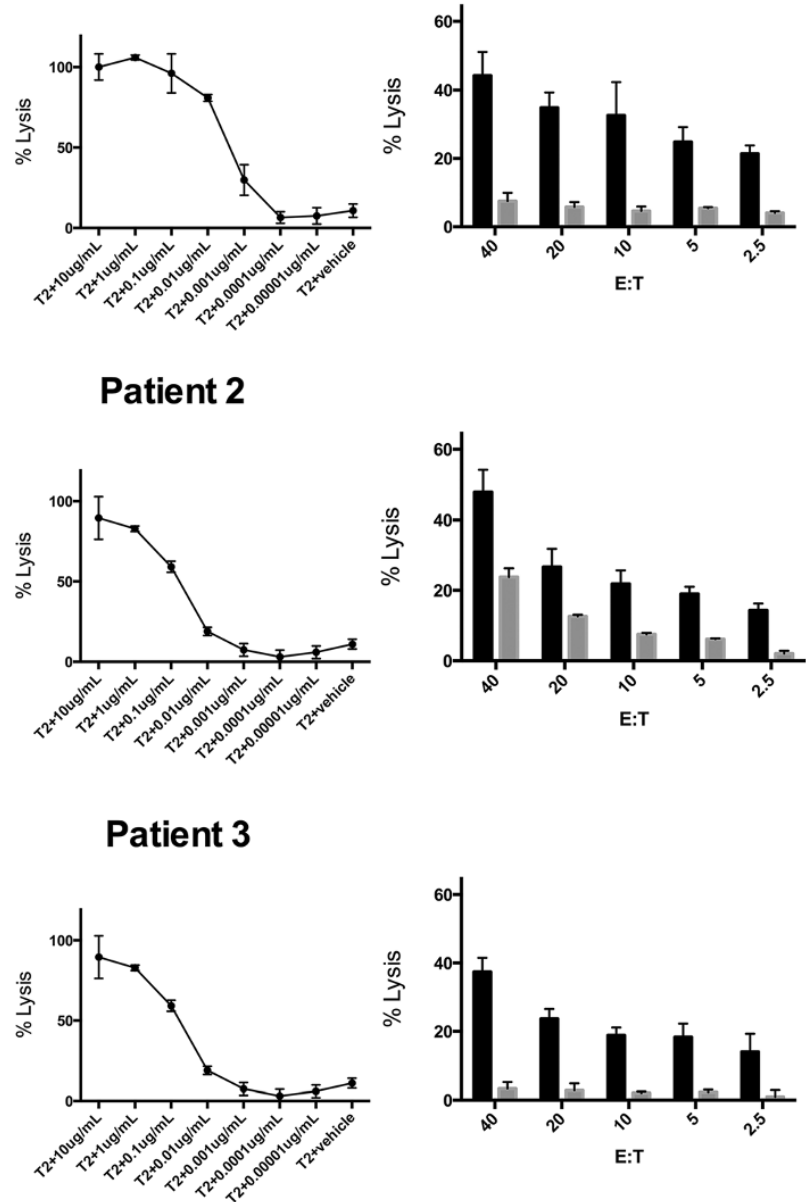

Patient 4


Patient 5
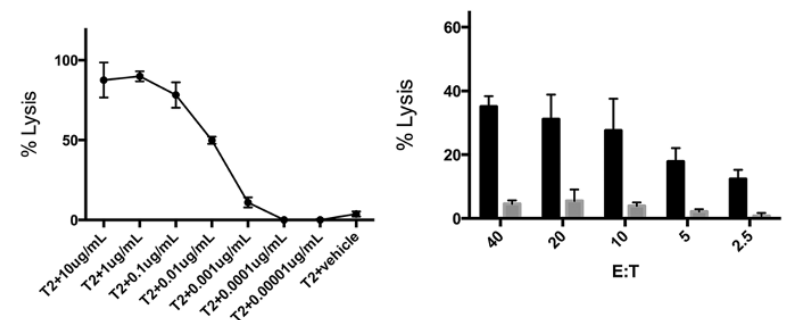

Patient 6


B
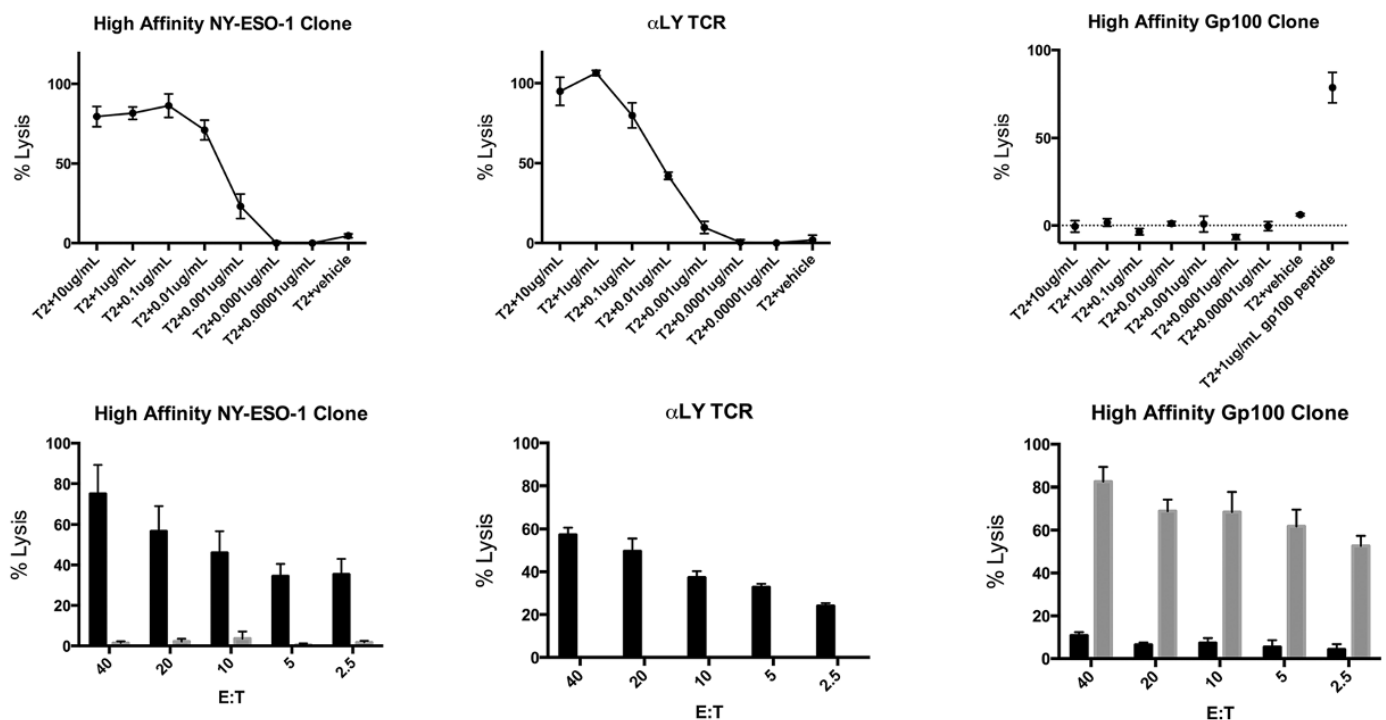

Mel A375

\section{Mel 526}


(See figure on previous page.)

Figure 2 Functional avidity of NY-ESO-1 specific T cells. A. NY-ESO-1 specific T cell products from patients \#1-\#6. The left panel for each patient shows the lysis of T2 cells pulsed with various concentrations of NY-ESO-1 peptide by NY-ESO-1-specific T cells at an effector to target (E:T) ratio of 20:1. The right panel shows lysis of the NY-ESO-1 expressing tumor cell line MelA375 at various E:T ratios. The tumor cell line Mel526 (NY-ESO-1 negative, gp100 positive) is a negative control. B. Lysis of NY-ESO-1 peptide pulsed T2 cells and tumor cells by a high affinity NY-ESO-1 T cell clone isolated by our lab, T cells transfected with the aLY TCR and sorted to $>80 \%$ purity with NY-ESO-1 tetramer, and a gp $100_{154-162}$ specific T cell clone.

melanoma and leukemia-associated antigens, a means to target more commonly expressed tumor-associated antigens using a method that is relatively expedient and clinically feasible would be desirable. To this end, we developed a clinically-approved approach to isolate endogenous antigen-specific $\mathrm{T}$ cells from the peripheral blood for adoptive therapy ("endogenous T cell" or ETC therapy). An unbiased source of $\mathrm{T}$ cells would be readily available from the peripheral blood in contrast to TIL therapy (where a surgically accessible tumor with an adequate population of infiltrating lymphocytes is required), In contrast to engineered TCR or CAR, no genetic modification is required and there is greater flexibility in targeting tumor-associated antigens. With ETC therapy, more rapid implementation of clinical studies is also possible since the only requirement is a new GMP-grade peptide whereas specific toxicities and binding properties associated with each new TCR or CAR construct need to be addressed. To demonstrate the feasibility of the form of ETC therapy presented in this study, we target a prototypic cancer testis antigen (CT antigen), NY-ESO-1, expressed in several solid tumor types including breast, colorectal, ovarian, lung cancer and sarcoma.

Patients with soft tissue sarcomas can express very high levels of NY-ESO-1 but the often undetectable levels of NY-ESO-1 specific $\mathrm{CD}^{+} \mathrm{T}$ cells in their peripheral blood has made it difficult to generate autologous NY-ESO-1 T cell products for adoptive immunotherapy. Here we demonstrated that after stimulating CD25 depleted T cells from sarcoma patients with autologous dendritic cells pulsed with the NY-ESO- $1_{157-165}$ peptide and in vitro exposure to IL-21, rare wells containing measurable tetramer positive $T$ cells can be identified and clinical grade cell sorting can be used to enrich and expand these populations to large numbers of highly purified tumor-reactive $\mathrm{T}$ cells. The cell products are oligoclonal, have an effector memory phenotype, and are of sufficient functional avidity to lyse T2 cells pulsed with low concentrations of NY-ESO-1 peptide, and tumor cell lines that express NY-ESO-1.

We were able to obtain regulatory approval from the FDA to use this methodology for the generation of clinical grade $\mathrm{T}$ cell products for the treatment of patients with advanced cancer. The selection reagents for cell sorting, peptide-MHC tetramer complexes conjugated to a fluorescence molecule, were tested for sterility, endotoxin and mycoplasma prior to GMP use in order to assure safety in these reagents in a GMP environment. While MHC streptamers (produced by IBA) offer the advantage of reversible binding to the target cell [24,25], there was no apparent impact on the ability to expand these cells after sorting and given the small amount of tetramer reagent used and the multiple washes occurring during the two expansions, any remaining tetramer present in the final product is unlikely to be clinically relevant and was not a concern for regulatory approval.

Other investigators have used retroviral and lentiviral vectors to insert an NY-ESO-1 specific TCR into T cells and redirect their specificity to tumor cells $[5,26]$. Genetic modification has the advantage of using an off the shelf reagent to engineer each patient's $T$ cells with an identical high affinity TCR. However, there are theoretical safety concerns related to the potential for cross pairing of the introduced TCR chains with endogenous chains to confer autologous reactivity [11] and the use of affinity-enhanced and xenogeneic TCR has also raised serious safety concerns related to recent patient deaths $[8,27]$. Practical considerations of genetically modifying cells for altered specificity such as the cost and regulatory burden are also significant issues for many labs. The ETC (endogenous $\mathrm{T}$ cell therapy) approach presented here, obviates many of these issues and can provide $T$ cell products that have comparable avidity and function to those generated by transfer of genes that encode a high affinity NY-ESO-1 specific TCR.

For this study, IL-21 was used to enrich for a population of CD8+ T cells with a central memory phenotype [19] which in our previous studies has demonstrated long-term in vivo persistence [28]. Our decision to set a target cell dose of $10^{10}$ cells $/ \mathrm{m}^{2}$ was based on prior studies where this dose range has been effective and allows for in vivo tracking of transferred $\mathrm{T}$ cells $[2,13,29]$. In light of the high replicative potential of IL-21 -primed CTL, a lower optimal cell dose may yet be determined; a lower dose requirement would allow for the collection of lower blood volumes and increase the feasibility of generating $\mathrm{T}$ cells to multiple targets from a single collection.

It is interesting to speculate on why the two final products tested by deep sequence were both over $85 \%$ comprised of a dominant clone and all products consisted of 15 or fewer clones. It may be that $\mathrm{T}$ cells specific for NY-ESO-1 are infrequently found in the natural repertoire. It is also likely that certain clones become 
dominant during the expansions following selection by cell sorting.

This was a small series limited to HLA A*0201 positive patients with NY-ESO-1 expressing sarcomas, accompanied by some variability among the NY-ESO-1 specific $\mathrm{T}$ cell products with regards to their lytic ability and expression of markers of $\mathrm{T}$ cell differentiation. However, clinical cell sorting with HLA tetramers offers a platform that can be easily adapted to additional MHC restricted targets (for example other $\mathrm{CT}$ antigens such as PRAME and MAGE family antigens), and additional HLA alleles. Moreover this approach may be used with other reagents for detecting tumor-reactive $\mathrm{T}$ cells such as CD137, where knowledge of the HLA restricting allele and tumor antigen is not necessary [30]. Antigenspecific CD4 T cells have also been shown to be effective for the treatment of patients with solid tumor malignancies and, with further development of the Class II tetramers, it will be possible to rapidly isolate such $\mathrm{T}$ cells in future trials $[3,31,32]$.

In summary, the results of this study demonstrate that rare tumor-reactive antigen-specific $\mathrm{T}$ cells can be successfully isolated from the peripheral blood of patients and expanded to numbers sufficient for adoptive therapy. By the use of in vitro stimulation as a means to augment the population of antigen-specific CTL in culture and enrich for a pool of CD28 hi helper-independent CD8+ T cells following exposure to IL-21, together with tetramer-guided cell sorting under clinical manufacturing conditions, it is feasible to generate tumor-reactive antigen-specific CTL of sufficient magnitude ( $>30$ billion) for therapy in 5-6 weeks from PBMC collection to $\mathrm{T}$ cell product. Strategies to further streamline this approach and validate the routine generation of $\mathrm{T}$ cells against additional target antigens such as WT-1, and additional CT family antigens that are expressed broadly in solid tumors, will facilitate entry of adoptive therapy into mainstream clinical practice and consideration as a possible treatment modality in patients with solid tumor malignancies.

\section{Conclusion}

NY-ESO-1 specific T cells can be isolated and expanded from the peripheral blood of patients with NY-ESO-1 expressing cancers under clinical manufacturing conditions for use in adoptive $\mathrm{T}$ cell therapy trials.

\section{Methods}

\section{Patients, sample acquisition and initial processing}

Patients were enrolled on protocols approved by the Fred Hutchinson Cancer Research Center (FHCRC) IRB for tissue and blood procurement between September 2011 and May 2012, and provided informed consent in accordance with the Helsinki Declaration. HLA typing of patient samples was performed at the Puget Sound Blood Center (PSBC). Patients that expressed HLA $\mathrm{A}^{*}$ 0201, had an ECOG performance status of 1 and tumor biopsies with positive staining for NY-ESO- 1 in $>25 \%$ of cells by immunohistochemistry underwent leukapheresis at either the PSBC or University of Washington General Clinical Research Center. All further processing of the leukapheresis product was performed at FHCRC in the Cell Professing Facility (CPF) under current Good Manufacturing Practice (cGMP) guidelines. A portion of the leukapheresis product $\left(2 \times 10^{9}\right.$ cells) was $\mathrm{CD} 25$ depleted on a CliniMACS system using clinical grade CD25 MicroBeads [Miltenyi Biotec, Auburn, CA, USA] to remove $\mathrm{CD} 4^{+}$ regulatory cells. Both the CD25-depleted mononuclear cell fraction, as well as the remaining unprocessed peripheral blood mononuclear cells (PBMC), were cryopreserved; the latter being used for dendritic cell (DC) generation.

\section{Culture of dendritic cells}

The protocols for DC generation have been described previously [33]. Briefly, PBMC were suspended in AIM-V medium at $3 \times 10^{\wedge} 6$ cells $/ \mathrm{mL}$, and then placed in sterile tissue culture dishes at $3 \mathrm{~mL} /$ well to separate plastic adherent and non-adherent populations by culture for 1 hour at $37^{\circ} \mathrm{C}$. Adherent cells were treated with GM-CSF $(800 \mathrm{U} / \mathrm{mL})$ [MP Biomedicals, Santa Ana, CA, USA] and IL-4 (500 U/ $\mathrm{mL}$ ) [R\&D Systems, Minneapolis, MN, USA] for 6 days to promote DC differentiation, and the DC were then matured for 2 days using a cytokine cocktail containing TNF$\alpha(10 \mathrm{ng} / \mathrm{mL}), \mathrm{IL}-1 \beta(2 \mathrm{ng} / \mathrm{mL}), \mathrm{IL}-6$ (1000 U/mL), PGE-2 $(1000 \mathrm{ng} / \mathrm{mL}$ ) [all from R\&D Systems, Minneapolis, MN, USA], IL-4 (500 U/mL) and GM-CSF (800 U/mL). Mature DC's were generally used fresh (without freezing or thawing) for the initial stimulation but excess DC's were frozen and frequently used in the second stimulation.

\section{Stimulation of NY-ESO-1 specific T cells}

DC's were pulsed for 2 hours with $10-40 \mu \mathrm{g} / \mathrm{mL}$ of the NY-ESO- $1_{157-165}$ peptide in PBS with $1 \%$ HSA, washed, irradiated (5000 rads), and then co-cultured in 48 well plates with CD25 depleted PBMC in RPMI, 25 mM HEPES, 2 $\mathrm{mM}$ L-glutamine, 10\% human AB serum (CTL medium) and $\beta 2$-microglobulin $(3 \mu \mathrm{g} / \mathrm{mL})$ [Scripps Laboratories, San Diego, CA, USA]. Each plate was seeded with $70 \times 10^{6}$ CD25 depleted PBMC and 1.8 to $5 \times 10^{6}$ DC's divided equally among the 48 wells. Two stimulations with peptide pulsed DC were performed 7 days apart. During the first stimulation, IL-21 (30 ng/mL) [Peprotech, Rocky Hill, NJ, USA] was added twice in the first 4 days, and during the second stimulation cycle, IL-21 $(30 \mathrm{ng} / \mathrm{mL})$ is added on the first day and IL-2 $(10 \mathrm{ng} / \mathrm{mL})$ [Bayer, Terrytown, NY, USA] and IL-7 (5 ng/mL) [R\&D Systems, Minneapolis, $\mathrm{MN}$, USA] were added on the first day and days two through four [18]. Stimulations for gp100 specific and 
MART1-specific $\mathrm{T}$ cells were performed using the same protocol using gp $100_{154-162}$ or $\mathrm{MART}_{27-35}$ peptides, respectively.

\section{Sorting and expansion}

After two stimulations, an aliquot of each well was stained with an HLA A*0201 MHC tetramer folded with the NY-ESO-1 $1_{157-165}$ peptide produced in the Immunologic Monitoring Core Facility at FHCRC. Wells that contained $>0.5 \%$ tetramer positive cells were pooled, sorted using only forward, side scatter and single color tetramer parameters on a clinically qualified INFLUX cell sorter [Becton Dickenson, Franklin Lakes, NJ, USA] located within the $\mathrm{CPF}$, and expanded using a rapid expansion protocol (REP) in a sterile $25 \mathrm{~mL}$ flask using an IL-2 concentration of $50 \mathrm{U} / \mathrm{mL}$ as previously described [34]. In some cases, wells with $<0.5 \%$ tetramer positive cells were sorted and expanded if there was clearly a distinct tetramer positive population. After expansion, a sample of the $\mathrm{T}$ cells were again stained with anti-CD8 $\mathrm{mAb}$ and NY-ESO-1 ${ }_{157-165}$ tetramer to determine the degree of enrichment of tetramer positive $\left(\right.$ tet $^{+}$) cells, and tested in a chromium release assay for lysis of T2 lymphocytes pulsed with NY-ESO-1 $1_{157-165}$ peptide. A final large volume expansion was performed using either bags [Lifecell, Branchburg, NJ, USA] or GREX flasks [Wilson-Wolf, St. Paul, MN, USA].

To facilitate detailed functional analysis, an aliquot of some $\mathrm{T}$ cell products was removed from the CPF after the first expansion, and expanded in the research lab for in vitro assays to assess recognition of target cells pulsed with various concentrations of peptide and to assess cytokine production in response to antigen stimulation. Cell surface phenotype and TCR V $\beta$ spectratyping were performed on aliquots from the second expansion.

\section{Phenotyping and functional analysis of NY-ESO-1-specific T cells}

Cell surface phenotype was determined by co-staining with NY-ESO-1 tetramer (APC) and the following fluorochrome conjugated antibodies: CD8 (BV421) [BD Bioscience, Franklin Lakes, NJ, USA], CD28 (PE- Texas Red) [Beckman Coulter, Brea Ca, USA], CD27 (BV711), CCR7 (PECy7), CD127 (PE) [all BD Pharmigen, San Diego, CA, USA], CD62L (APC-eFluor780) [Biolegend, San Diego, CA, USA], and CD45RO (FITC) [Invitrogen, Grand Island, NY]. Cells were analyzed on an LSRII [Becton Dickinson, Franklin Lakes, NJ, USA] using FlowJo software.

The NY-ESO-1 specificity of the expanded T cell products was confirmed using chromium release assay performed on day 12 of the REP. T2 lymphocytes cultured alone for 2 hours or in media with the NY-ESO-1 157-165 peptide and HLA A*0201 positive, NY-ESO-1 positive tumor line Mel A375 (A375) were used as target cells.
In order to test NY-ESO-1 specific CTL lines in sarcoma tumor lines, the SS cell line SYO-1 (gift of Dr. Akira Kawai [35]) and the MRCL cell line 402 (gift of Pierre Aman [36] ) were used. Because neither of these cell lines are positive for HLA A*0201, they were transfected with the lentivirus pRRLSIN with A*0201 cloned into it. To further purify the $A^{*} 0201$ expressing population, tumor cells were stained using an antibody for A02 (PE) [BD Pharmigen, San Diego, CA, USA] then sorted using a FACSAria cell sorter (Becton Dickson) to isolate A02 expressing tumor cells. Cell were then grown in culture and confirmed to express A02 by flow cytometry prior to chromium release assay.

Target cells were labeled with $100 \mu \mathrm{Ci}{ }^{51} \mathrm{Cr}$ in $1 \mathrm{~mL}$ of media and co-cultured with effector T cells for 4-6 hours at $37^{\circ} \mathrm{C}$ plus $5 \% \mathrm{CO}_{2}$ at a $20: 1$ effector to target (E:T) ratio unless otherwise specified. Chromium release experiments were performed in sextuplicate and to remove outliers in a consistent fashion, the highest and lowest values for each target/effector ratio were discarded. As a positive control, we tested an NY-ESO-1-specific T cell clone generated in our lab [23], and $\mathrm{T}$ cells transduced with the $\alpha$ LY NY-ESO-1 specific TCR [26] (gift of Paul Robbins courtesy of Dr. E.H. Warren).

For cytokine analysis, $\mathrm{T}$ cells were incubated overnight at a 20:1 E:T ratio (200,000 effectors with 10,000 targets) in $200 \mu \mathrm{L}$ CTL media with T2 lymphocytes alone or with T2 lymphocytes pulsed with NY-ESO- $1_{157-165}$ peptide $(10 \mu \mathrm{g} / \mathrm{mL})$ for 2 hours and then washed before plating in the assay. Supernatant was analyzed for using a luminex assay for IFN-gamma (Fisher) and TNF alpha [R\&D Systems, Minneapolis, MN, USA].

\section{Immunohistochemistry}

Immunohistochemical staining for all SS and MRCL patients was performed at the University of Washington Pathology lab with mAb specific for NY-ESO-1 (1:100, E978 clone, Life Technologies, Grand Island, NY) using an automated immunostainer (Bond III). Testis was used as a positive control.

\section{Spectratyping and deep sequencing of $\mathrm{T}$ cell receptors}

TCR $\beta$-chain spectratype analysis was performed by the Immune Monitoring Laboratory at Fred Hutchinson Cancer Research Center according to the protocol developed by Akatsuka et al. [37] Briefly, cDNA was generated from 1-5 $\times 10^{6}$ cells and five multiplex PCR reactions were run to amplify the CDR3 variable regions of each of the 23 TCR $\beta$-chain families. The PCR products were analyzed by capillary electrophoresis on the $3730 \mathrm{xl}$ DNA analyzer and GeneMapper software [Life Technologies/ Applied Biosystems, Van Allen Way, Ca, USA]. TCR V $\beta$ sequencing and normalization was performed by Adaptive Biotechnologies [Seattle, WA, USA]. 


\section{Additional file}

Additional file 1: Figure S1. Results after 2 stimulations of PBMC from a melanoma patient using DC's pulsed with the MART-1 27-35 peptide. Figure S2. CD8 and NY-ESO-1 Tetramer staining of fully expanded, clinical grade products. Figure S3. Expression of markers of memory phenotype CD45RO, CD27, CD28, CD62L, CCR7, and CD127 (blue) and controls (red). Figure S4. IFN gamma and TNF alpha of fully expanded clinical grade products following co-culture with peptide pulsed and un-pulsed T2 lymphocytes. Figure S5. Chromium release assay demonstrating specific lysis of the SS tumor line SYO-1 and the MRCL tumor line 402 at a 20:1 effector to target ratio. Because these tumor lines do not express the HLA A*0201, they were transfected with a lentivirus encoding for $A^{*} 0201$, purified for the A02 expressing cells by flow sorting and grown in culture prior to this assay. Figure S6. V $\beta$ spectratyping of each fully expanded clinical products. Figure S7. T cell products are oligoclonal.

\section{Abbreviations}

A/I: Adiamycin and Ifosfamide; DC: Dendritic Cell; DTIC: Decarbazine; CAR: Chimeric Antigen Receptor; cGMP: current Good Manufacturing Practice; CPF: Cell Processing Facility; CT Antigens: Cancer-Testis Antigens; CTL: Cytotoxic T Lymphocytes; Doxil: Liposomal Doxorubicin; E:T: Effector to Target Ratio; Gem/tax: gemcitabine and docetaxel; GM-CSF: Ganulocyte Macrophage Colony Stimulating Factor; HLA: Human Leukocyte Antigen; IFN: Interferon; PBMC: Peripheral Blood Mononuclear Cell; mAb: Monoclonal antibody; MHC: Major Histocompatibility Complex; MRCL: Myxoid/ Round Cell Liposarcoma; REP: Rapid Expansion Protocol; RTX: Radiation Therapy; SS: Synovial Sarcoma; TCR: T cell Receptor; Tet: MHC tetramer; TNF: Tumor Necrosis Factor.

\section{Competing interests}

CY holds a patent for the use of IL-21 to generate antigen-specific T cells.

\section{Authors' contributions}

SMP and CY conceptualized and planned all experiments, analyzed all data, and prepared the manuscript. RLJ, JFE and EUC participated in patient acquisition and manuscript preparation. EF, IPL and SML performed cell culture, flow cytometry and assays regarding T cell function. BLH and AG tested NY-ESO-1 expression and the confirmed histologic sarcoma subtype for all patients. VP and KS assisted with flow cytometry and manuscript preparation. JC performed spectratyping and GMP quality tetramer production. $\mathrm{MB}$ and $\mathrm{EHW}$ provided key reagents and assisted in manuscript preparation. JNC and SH oversaw GMP quality cell production and assisted with manuscript preparation. SRR played a critical role in the conceptualization of all experiments, data analysis and manuscript preparation.

\section{Funding}

JFE is supported by NIH/NCI R01 65537-16.

SH is supported by P30 CA15704, P01 CA18029 and P30 DK56465.

$\mathrm{RLJ}$ is supported by the Gilman Sarcoma Foundation.

SMP is supported by the Sarcoma Alliance for Research through Collaboration (SARC) Career Development Award, the Doug and Maggie Walker Immunotherapy Fellowship, 1K23CA175167-01, and the Gilman Sarcoma Foundation.

MB is the Damon Runyon-Richard Lumsden Foundation Clinical Investigator supported in part by the Damon Runyon Cancer Research Foundation (Cl-57-11), and in part by K23CA154532-01 from the National Cancer Institute. SRR is supported by R01 CA136551 and R01 CA114536.

EHW is supported by the Multiple Myeloma Research Foundation.

$\mathrm{CY}$ is a recipient of a Clinical Scientist in Translational Research Award from Burroughs Wellcome Fund.

The content is solely the responsibility of the authors and does not necessarily represent the official views of the National Cancer Institute, the National Institutes of Health or any other sponsor of this work.

\section{Author details}

${ }^{1}$ Clinical Research Division, D3-100 Fred Hutchinson Cancer Research Center, 1100 Fairview Ave, Seattle, WA 98109, USA. ${ }^{2}$ Department of Medicine, University of
Washington, Seattle, WA, USA. ${ }^{3}$ Department of Surgery, University of Washington, Seattle, WA, USA. ${ }^{4}$ Department of Pathology, University of Washington, Seattle, WA, USA. ${ }^{5}$ Department of Pediatrics, University of Washington, Seattle, WA, USA. ${ }^{6}$ Department of Orthopedics, University of Washington, Seattle, WA, USA. ${ }^{7}$ Department of Radiology, University of Alabama, Birmingham, AL, USA. ${ }^{8}$ Institute for Advanced Study, Technical University of Munich, Munich, Germany. ${ }^{9}$ Department of Melanoma Medical Oncology, UT MD Anderson Cancer Center, 7455 Fannin St, Unit 904, Houston, TX 77054, USA.

Received: 13 May 2014 Accepted: 9 September 2014 Published online: 14 October 2014

\section{References}

1. Restifo NP, Dudley ME, Rosenberg SA: Adoptive immunotherapy for cancer: harnessing the T cell response. Nat Rev Immunol 2012, 12:269-281.

2. Chapuis AG, Thompson JA, Margolin KA, Rodmyre R, Lai IP, Dowdy K, Farrar EA, Bhatia S, Sabath DE, Cao J, Li Y, Yee C: Transferred melanoma-specific CD8+ T cells persist, mediate tumor regression, and acquire central memory phenotype. Proc Natl Acad Sci U S A 2012, 109(12):4592-4597. doi: 10.1073/pnas.1113748109. Epub 2012 Mar 5.

3. Hunder NN, Wallen H, Cao J, Hendricks DW, Reilly JZ, Rodmyre R, Jungbluth A, Gnjatic S, Thompson JA, Yee C: Treatment of metastatic melanoma with autologous CD4+ T cells against NY-ESO-1. N Engl J Med 2008, 358:2698-2703.

4. Park JR, Digiusto DL, Slovak M, Wright C, Naranjo A, Wagner J, Meechoovet HB, Bautista C, Chang WC, Ostberg JR, Jensen MC: Adoptive transfer of chimeric antigen receptor re-directed cytolytic T lymphocyte clones in patients with neuroblastoma. Mol Ther 2007, 15:825-833.

5. Robbins PF, Morgan RA, Feldman SA, Yang JC, Sherry RM, Dudley ME, Wunderlich JR, Nahvi AV, Helman LJ, Mackall CL, Kammula US, Hughes MS, Restifo NP, Raffeld M, Lee CC, Levy CL, Li YF, El-Gamil M, Schwarz SL, Laurencot $C$, Rosenberg $S A$ : Tumor regression in patients with metastatic synovial cell sarcoma and melanoma using genetically engineered lymphocytes reactive with NY-ESO-1. J Clin Oncol 2011, 29(7):917-924. doi: 10.1200/JCO.2010.32.2537. Epub 2011 Jan 31.

6. Porter $\mathrm{DL}$, Levine $\mathrm{BL}$, Kalos $\mathrm{M}$, Bagg A, June $\mathrm{CH}$ : Chimeric antigen receptor-modified T cells in chronic lymphoid leukemia. N Engl J Med 2011, 365:725-733.

7. Brentjens RJ, Davila ML, Riviere I, Park J, Wang X, Cowell LG, Bartido S, Stefanski J, Taylor C, Olszewska M, Borquez-Ojeda O, Qu J, Wasielewska T, He Q, Bernal Y, Rijo IV, Hedvat C, Kobos R, Curran K, Steinherz P, Jurcic J, Rosenblat T, Maslak P, Frattini M, Sadelain M: CD19-targeted T cells rapidly induce molecular remissions in adults with chemotherapy-refractory acute lymphoblastic leukemia. Sci Transl Med 2013, 5(177):177ra138. doi: 10.1126/scitranslmed.3005930.

8. Morgan RA, Chinnasamy N, Abate-Daga D, Gros A, Robbins PF, Zheng Z, Dudley ME, Feldman SA, Yang JC, Sherry RM, Phan GQ, Hughes MS, Kammula US, Miller AD, Hessman CJ, Stewart AA, Restifo NP, Quezado MM, Alimchandani M, Rosenberg AZ, Nath A, Wang T, Bielekova B, Wuest SC, Akula N, McMahon FJ, Wilde S, Mosetter B, Schendel DJ, Laurencot CM, et al: Cancer regression and neurological toxicity following anti-MAGE-A3 TCR gene therapy. J Immunother 2013, 36(2):133-151. doi: 10.1097/CJl.0b013e3182829903.

9. Morgan RA, Dudley ME, Wunderlich JR, Hughes MS, Yang JC, Sherry RM, Royal RE, Topalian SL, Kammula US, Restifo NP, Zheng Z, Nahvi A, de Vries CR, Rogers-Freezer $\sqcup$, Mavroukakis SA, Rosenberg SA: Cancer regression in patients after transfer of genetically engineered lymphocytes. Science 2006, 314(5796):126-129. Epub 2006 Aug 31.

10. Kalos M, Levine BL, Porter DL, Katz S, Grupp SA, Bagg A, June CH: T cells with chimeric antigen receptors have potent antitumor effects and can establish memory in patients with advanced leukemia. Sci Transl Med 2011, 3:95ra73.

11. Bendle GM, Linnemann C, Hooijkaas Al, Bies L, de Witte MA, Jorritsma A Kaiser AD, Pouw N, Debets R, Kieback E, Uckert W, Song JY, Haanen JB, Schumacher TN: Lethal graft-versus-host disease in mouse models of $T$ cell receptor gene therapy. Nat Med 2010, 16(5):565-570. 1p following 570. doi: 10.1038/nm.2128. Epub 2010 Apr 18.

12. Coccoris M, Straetemans T, Govers C, Lamers C, Sleijfer S, Debets R: T cell receptor (TCR) gene therapy to treat melanoma: lessons from clinical and preclinical studies. Expert Opin Biol Ther 2010, 10:547-562. 
13. Yee C, Thompson JA, Byrd D, Riddell SR, Roche P, Celis E, Greenberg PD: Adoptive $T$ cell therapy using antigen-specific CD8+ T cell clones for the treatment of patients with metastatic melanoma: in vivo persistence, migration, and antitumor effect of transferred T cells. Proc Natl Acad Sci U S A 2002, 99:16168-16173.

14. Butler MO, Friedlander P, Milstein MI, Mooney MM, Metzler G, Murray AP, Tanaka M, Berezovskaya A, Imataki O, Drury L, Brennan L, Flavin M, Neuberg D, Stevenson K, Lawrence D, Hodi FS, Velazquez EF, Jaklitsch MT, Russell SE, Mihm M, Nadler LM, Hirano N: Establishment of antitumor memory in humans using in vitro-educated CD8+ T cells. Sci Trans/ Med 2011, 3(80):80ra34. doi: 10.1126/scitranslmed.3002207.

15. Dannull J, Su Z, Rizzieri D, Yang BK, Coleman D, Yancey D, Zhang A, Dahm P, Chao N, Gilboa E, Vieweg J: Enhancement of vaccine-mediated antitumor immunity in cancer patients after depletion of regulatory T cells. J Clin Invest 2005, 115:3623-3633.

16. Attia P, Powell DJ Jr, Maker AV, Kreitman RJ, Pastan I, Rosenberg SA: Selective elimination of human regulatory $T$ lymphocytes in vitro with the recombinant immunotoxin LMB-2. J Immunother 2006, 29:208-214.

17. Rasmussen AM, Borelli G, Hoel HJ, Lislerud K, Gaudernack G, Kvalheim G, Aarvak T: Ex vivo expansion protocol for human tumor specific T cells for adoptive T cell therapy. J Immunol Methods 2010, 355:52-60.

18. Li Y, Yee C: IL-21 mediated Foxp3 suppression leads to enhanced generation of antigen-specific CD8+ cytotoxic T lymphocytes. Blood 2008, 111:229-235.

19. Li Y, Bleakley M, Yee C: IL-21 influences the frequency, phenotype, and affinity of the antigen-specific CD8 T cell response. J Immunol 2005, 175:2261-2269.

20. Pollack SM, Jungbluth AA, Hoch BL, Farrar EA, Bleakley M, Schneider DJ, Loggers ET, Rodler E, Eary JF, Conrad EU III, Jones RL, Yee C: NY-ESO-1 is a ubiquitous immunotherapeutic target antigen for patients with myxoid/ round cell liposarcoma. Cancer 2012, 118(18):4564-4570. doi: 10.1002/ cncr.27446. Epub 2012 Feb 22.

21. Jungbluth AA, Antonescu CR, Busam K, Iversen K, Kolb D, Coplan K, Chen YT, Stockert E, Ladanyi M, Old L: Monophasic and biphasic synovial sarcomas abundantly express cancer/testis antigen NY-ESO-1 but not MAGE-A1 or CT7. Int J Cancer 2001, 94:252-256.

22. Singer S, Baldini EH, Demetri GD, Fletcher JA, Corson JM: Synovial sarcoma: prognostic significance of tumor size, margin of resection, and mitotic activity for survival. J Clin Oncol 1996, 14:1201-1208.

23. Pollack SM, Li Y, Blaisdell MJ, Farrar EA, Chou J, Hoch BL, Loggers ET, Rodler E, Eary JF, Conrad EU III, Jones RL, Yee C: NYESO-1/LAGE-1s and PRAME Are targets for antigen specific $t$ cells in chondrosarcoma following treatment with 5-Aza-2-Deoxycitabine. PLoS One 2012, 7(2):e32165. doi: 10.1371/journal.pone.0032165. Epub 2012 Feb 27.

24. Neudorfer J, Schmidt B, Huster KM, Anderl F, Schiemann M, Holzapfel G, Schmidt T, Germeroth L, Wagner H, Peschel C, Busch DH, Bernhard H: Reversible HLA multimers (Streptamers) for the isolation of human cytotoxic T lymphocytes functionally active against tumor- and virus-derived antigens. J Immunol Methods 2007, 320(1-2):119-131. Epub 2007 Jan 31.

25. Wang X, Schmitt A, Chen B, Xu X, Mani J, Linnebacher M, Freund M, Schmitt M: Streptamer-based selection of WT1-specific CD8+ T cells for specific donor lymphocyte infusions. Exp Hematol 2010, 38:1066-1073.

26. Robbins PF, Li YF, El-Gamil M, Zhao Y, Wargo JA, Zheng Z, Xu H, Morgan RA, Feldman SA, Johnson LA, Bennett AD, Dunn SM, Mahon TM, Jakobsen BK, Rosenberg SA: Single and dual amino acid substitutions in TCR CDRs can enhance antigen-specific T cell functions. J Immunol 2008, 180(9):6116-6131.

27. Linette GP, Stadtmauer EA, Maus MV, Rapoport AP, Levine BL, Emery L, Litzky L, Bagg A, Carreno BM, Cimino PJ, Binder-Scholl GK, Smethurst DP, Gerry AB, Pumphrey NJ, Bennett AD, Brewer JE, Dukes J, Harper J, TaytonMartin HK, Jakobsen BK, Hassan NJ, Kalos M, June CH: Cardiovascular toxicity and titin cross-reactivity of affinity enhanced $\mathrm{T}$ cells in myeloma and melanoma. Blood 2013, 122(6):863-871. doi: 10.1182/blood-2013-03490565. Epub 2013 Jun 14

28. Chapuis AG, Ragnarsson GB, Nguyen HN, Chaney CN, Pufnock JS, Schmitt TM, Duerkopp N, Roberts IM, Pogosov GL, Ho WY, Ochsenreither S, Wölfl M, Bar M Radich JP, Yee C, Greenberg PD: Transferred WT1-reactive CD8+ T cells can mediate antileukemic activity and persist in post-transplant patients. Sci Transl Med 2013, 5(174):174ra27. doi: 10.1126/scitranslmed.3004916.
29. Chapuis AG, Afanasiev OK, lyer JG, Paulson KG, Parvathaneni U, Hwang JH, Lai I, Roberts IM, Sloan HL, Bhatia S, Shibuya KC, Gooley T, Desmarais C, Koelle DM, Yee C, Nghiem P: Regression of metastatic Merkel cell carcinoma following transfer of polyomavirus-specific T cells and therapies capable of re-inducing HLA class-I. Cancer Immunol Res 2014 2(1):27-36. doi: 10.1158/2326-6066.CIR-13-0087.

30. Wolfl M, Kuball J, Ho WY, Nguyen H, Manley TJ, Bleakley M, Greenberg PD: Activation-induced expression of CD137 permits detection, isolation, and expansion of the full repertoire of CD8+ T cells responding to antigen without requiring knowledge of epitope specificities. Blood 2007, 110:201-210.

31. Ayyoub M, Pignon P, Classe JM, Odunsi K, Valmori D: CD4+ T effectors specific for the tumor antigen NY-ESO-1 are highly enriched at ovarian cancer sites and coexist with, but are distinct from, tumor-associated Treg. Cancer Immunol Res 2013, 1:303-308.

32. Yang J, James EA, Huston L, Danke NA, Liu AW, Kwok WW: Multiplex mapping of CD4 T cell epitopes using class II tetramers. Clin Immunol 2006, 120:21-32.

33. Bender A, Sapp M, Schuler G, Steinman RM, Bhardwaj N: Improved methods for the generation of dendritic cells from nonproliferating progenitors in human blood. J Immunol Methods 1996, 196:121-135.

34. Riddell SR, Greenberg PD: The use of anti-CD3 and anti-CD28 monoclonal antibodies to clone and expand human antigen-specific $T$ cells. $\mathrm{J}$ Immunol Methods 1990, 128:189-201.

35. Kawai A, Naito N, Yoshida A, Morimoto Y, Ouchida M, Shimizu K, Beppu Y: Establishment and characterization of a biphasic synovial sarcoma cell line, SYO-1. Cancer Lett 2004, 204:105-113.

36. Aman $\mathrm{P}$, Ron D, Mandahl $\mathrm{N}$, Fioretos $\mathrm{T}$, Heim $\mathrm{S}$, Arheden $\mathrm{K}$, Willen $\mathrm{H}$, Rydholm A, Mitelman F: Rearrangement of the transcription factor gene CHOP in myxoid liposarcomas with $t(12 ; 16)(q 13 ; p 11)$. Genes Chromosomes Cancer 1992, 5:278-285.

37. Akatsuka Y, Martin EG, Madonik A, Barsoukov AA, Hansen JA: Rapid screening of T-cell receptor (TCR) variable gene usage by multiplex PCR: application for assessment of clonal composition. Tissue Antigens 1999, 53:122-134

doi:10.1186/s40425-014-0036-y

Cite this article as: Pollack et al:: Tetramer guided, cell sorter assisted production of clinical grade autologous NY-ESO-1 specific CD8 ${ }^{+} \mathrm{T}$ cells. Journal for ImmunoTherapy of Cancer 2014 2:36.

\section{Submit your next manuscript to BioMed Central and take full advantage of:}

- Convenient online submission

- Thorough peer review

- No space constraints or color figure charges

- Immediate publication on acceptance

- Inclusion in PubMed, CAS, Scopus and Google Scholar

- Research which is freely available for redistribution 